International Journal of Automotive and Mechanical Engineering (IJAME)

ISSN: 2229-8649 (Print); ISSN: 2180-1606 (Online); Volume 6, pp. 680-691, July-December 2012

(OUniversiti Malaysia Pahang

DOI: http://dx.doi.org/10.15282/ijame.6.2012.1.0055

\title{
EFFECT OF WORKPIECE VOLUME ON SHELL WALL THICKNESS REDUCTION IN RAPID CASTING OF ALUMINUM USING THREE-DIMENSIONAL PRINTING
}

\author{
Rupinder Singh and Rajinder Singh \\ Department of Production Engineering \\ Guru Nanak Dev Engineering College, Ludhiana-141006, India \\ Phone: +91 98722 57575, Fax: +91 1612502700 \\ E-mail: rupindersingh78@yahoo.com
}

\begin{abstract}
The purpose of the present work is to study the effect of workpiece volume on reducing the shell wall thickness in rapid shell casting based upon three-dimensional printing (3DP) technology, and to evaluate the dimensional accuracy and mechanical properties of aluminum (Al) castings obtained as per the ISO standard UNIEN 20286-I (1995). Starting from the identification of component/benchmark, castings of different volumes (corresponding to workpieces of $\Phi 60 \mathrm{~mm}, \Phi 50 \mathrm{~mm}$ and $\Phi 40 \mathrm{~mm}$ ) were produced with different shell wall thicknesses. Measurements on a coordinate measuring machine (CMM) allowed the calculation of the dimensional tolerances of the castings produced. Some important mechanical properties were also compared to verify the suitability of the castings. The research proved that having a shell wall thickness with a value less than that recommended $(12 \mathrm{~mm})$ is more suitable from a dimensional accuracy and economic point of view (irrespective of the workpiece volume within the given selected range). All the castings produced with different shell thicknesses are acceptable as per the ISO standard. The results of the study suggest that workpiece volume has an unnoticeable effect on reducing the shell wall thickness for the selected range of volumes of casting. Furthermore, the hardness of castings produced is almost same for all shell wall thicknesses, from $12 \mathrm{~mm}$ to $1 \mathrm{~mm}$. The results are supported by cooling (time-temperature) curves, which show unnoticeable changes in the rate of heat transfer at different shell wall thicknesses. Keeping in mind the cost effectiveness of the process, one (1) mm shell wall thickness has been recommended for the production of castings. For a $1 \mathrm{~mm}$ shell wall thickness, the production cost and time are reduced by $67.38 \%$ and $44.87 \%$ (for $\Phi 60 \mathrm{~mm}$ workpieces), $64.51 \%$ and $44.62 \%$ (for $\Phi 50 \mathrm{~mm}$ workpieces), and $69.50 \%$ and $59.64 \%$ (for $\Phi 40 \mathrm{~mm}$ workpieces), respectively.
\end{abstract}

Keywords: Three-dimensional printing; workpiece volume; rapid casting; aluminum alloys; dimensional accuracy.

\section{INTRODUCTION}

Rapid prototyping (RP) is a fabrication method whereby physical objects are constructed by depositing material layer by layer under computer control (Singh, 2008a; Verma, 2008). RP takes virtual designs (from computer aided design (CAD) or from animation modeling software), transforms them into cross-sections, still virtual, and then creates each cross-section in physical space, one after the next until the model is finished (Singh, 2008b). The various commercially available RP processes can be classified on the basis of the base material used to make the prototype (Stampfl and 
Liska, 2005). Three-dimensional printing (3DP) is a relatively new form of RP (Singh and Verma, 2008; Singh, 2011b). The process of 3DP was patented in 1994 by Sachs et al. (1994) under U.S. patent number 005340656. It was developed at the Massachusetts Institute of Technology (MIT) and licensed to Soligen Corporation, Extrude Hone and Z Corporation of Burlington (Singh and Singh, 2009a). The techniques based on layer-bylayer manufacturing have extended their field of application, from the building of aesthetic and functional prototypes to the production of tools and molds for technological prototypes (Karapatis et al., 1998). In particular, additive construction applied to the production of dies and electrodes, directly from digital data, is defined as rapid tooling (RT) (Chua and Ho, 1999a). Patterns, cores and cavities for metal castings can be obtained through rapid casting (RC) techniques (Singh and Singh, 2009b). In both cases, since the tooling phase is highly time-consuming, great competitive advantages can be gained (Lee et al., 2004). Moreover, RT and RC processes allow the simultaneous development and validation of the product and of the manufacturing process (Chua and Ho, 1999b). Technological prototypes can constitute a strategic means, not only for functional and assembly tests or to obtain the customer's acceptance, but mainly to outline eventual critical points in the production process (Singh and Singh, 2009c). The relevance of RC techniques consists, above all, in a short time for parts availability (Bassoli et al., 2007). Traditionally, in order to produce cast prototypes a model and eventual cores have to be created, involving time and costs that hardly match the rules of a competitive market (Chan et al., 2003). For this reason functional tests are typically performed on prototypes obtained by metal cutting, which are not effective in outlining the issues related to the manufacturing process (Chhabra and Singh, 2011). The possibility of verifying the usefulness of a technological solution in the early stages of a product's development, ensures a 'concurrent engineering' approach and minimizes the risk of later modifications to the definitive production tools (Chua et al., 2005). The initial cost increase can thus be repaid through a reduction in costs and time for the following phases of development, engineering and production, as well as through non-monetary advantages (Bernard et al., 2003). In particular, for relatively small and complex parts the benefits of additive construction can be significant (Wang et al., 1999). In this field, innovative solutions are now available based on 3DP process, which can extend RC possibilities thanks to lower costs with respect to previous technologies, such as the laminated object manufacturing of sand casting (Singh and Singh, 2009c). One such technological solution in shell casting starts from starch patterns produced on 3DP conceptual modelers (Dimitrov et al., 2006). A second solution is 3DP technology with the use of a ceramic material which allows the production of complex cavities and cores, suitable for casting light alloys (Radstok, 1999). A key issue regarding the shell casting process is the production of the pattern in the case of prototype casting, for which traditional die casting is uneconomical (Cheah et al., 2005; Singh, 2008b). RP techniques can meet this requirement, producing single/few parts in a short time and without tooling costs (Dimitrov et al., 2007).

The present research regards shell patterns obtained by 3DP on which the ceramic shell can be built and then joined (as in the conventional process) to obtain the cavity for pouring metal. In 3DP, parts are built upon a platform situated in a bin full of powder material. Powdered material is distributed in the form of one layer at a time and selectively hardened and joined together by depositing drops of binder from a mechanism similar to that used for ink-jet printing (Singh, 2008a). Then a piston lowers the part so that the next layer of powder can be applied. For each layer, powder hopper and roller systems distribute a thin layer of powder over the top of the work tray. 
Adapted continuous-jet printing nozzles apply binder during a raster scan of the work area, selectively hardening the part's cross-section. The loose powder that was not hardened remains and acts as a support for the subsequent layers. The process is repeated until the part is completed. When finished, the green part is then removed from the unbound powder, and excess unbound powder is blown off. Finished parts can be infiltrated with wax, glue, or other sealants to improve their durability and surface finish (Singh, 2008c).

Experimental studies regarding this solution are lacking in the literature, in particular the technological feasibility of thin-walled parts needs to be assessed (Kaplas and Singh, 2008; Singh, 2011a). Furthermore, the literature review reveals that many researchers have worked at reducing the shell wall thickness for cost effective RC solutions (Verma, 2008). But hitherto no one has reported the effect of workpiece volume on reducing the wall thickness from that recommended $(12 \mathrm{~mm})$ in aluminum (Al) shell casting, in order to reduce the cost and time of shell production as well as to evaluate dimensional accuracy and mechanical properties. The outcome of the experimental study will be helpful in providing data for industrial applications of the considered technology. Following are the main objectives of the research work.

1. To study the effect of workpiece volume for reducing the recommended shell thickness in rapid shell casting, in order to reduce the shell production cost and time.

2. To evaluate the dimensional accuracy of the castings obtained and to check the consistency of the tolerance grades (IT Grades) of the castings as per the ISO standard (UNI EN 20286-I, 1995) for industrial applications.

\section{EXPERIMENTATION}

In order to accomplish the above objectives, 'Al alloy' has been chosen as a benchmark. The component selected for the present study is shown in Figure 1. For the process of $\mathrm{RC}$, based on 3DP, the following phases have been planned:

1. After the selection of the benchmark, the component to be built was modeled using CAD (Figure 2). The CAD software used for the modeling was UNIGRAPHICS Ver. NX 5.

2. The shells of the pattern were made at different thicknesses. The thickness values for the shells were $12,11,10,9,8,7,6,5,4,3,2$ and $1 \mathrm{~mm}$. Figure 3 shows the CAD model of the shell for $6 \mathrm{~mm}$ thickness.

3. The CAD models of shells were converted in to STL (standard triangulation language) format, also known as stereo lithography format (Figure 4).

4. Molds were manufactured in 3DP (Z Print machine, Model Z 510) with Z Cast 501 powder, and parts were heat treated at a temperature of $110^{\circ} \mathrm{C}$ for 1 hour. Figure 5 shows the post curing of shells in the oven. 

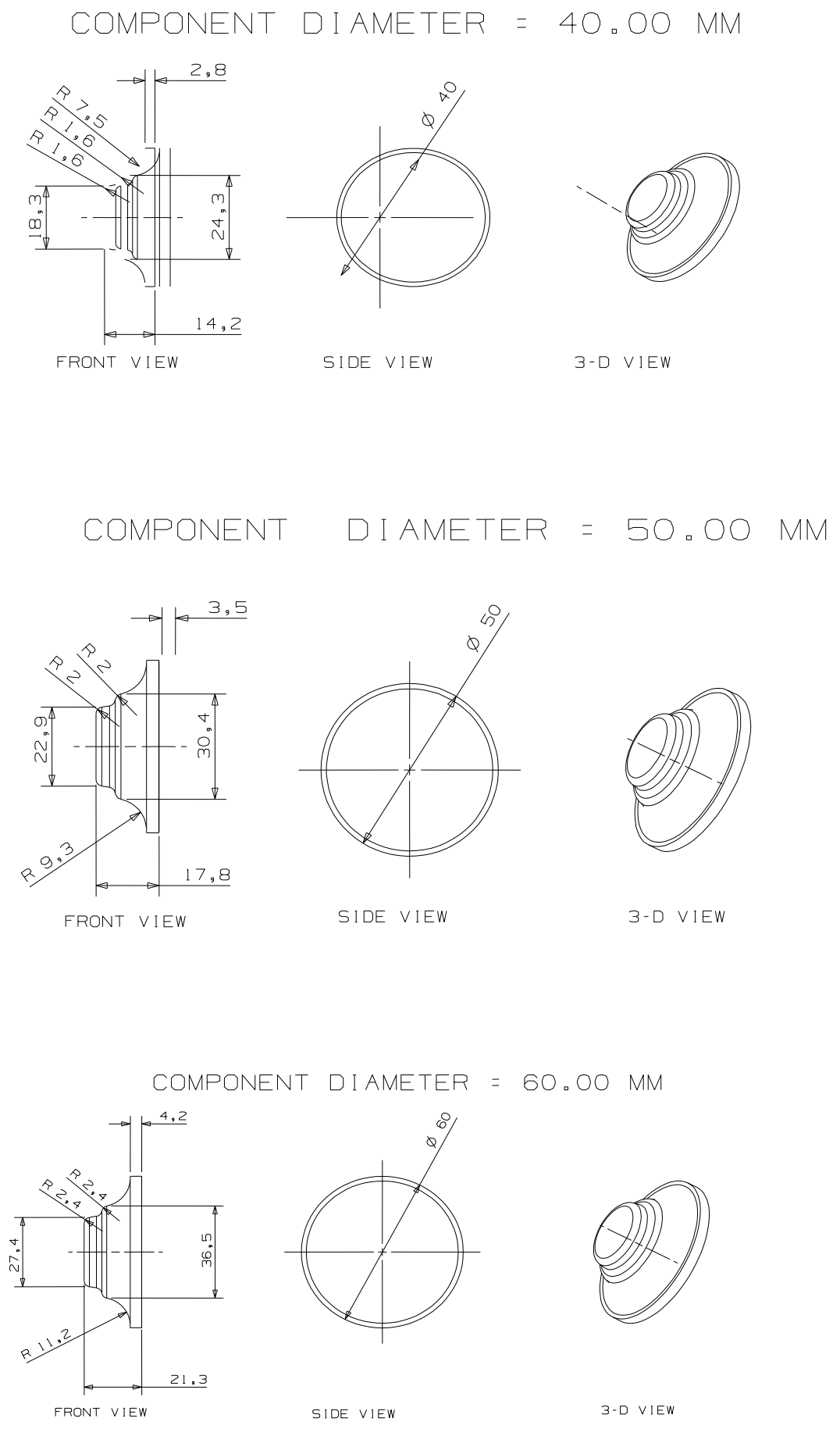

Figure 1. Orthographic view of benchmark

RP shell models have been used as the positive patterns around which the green sand (AFS No. 56) was filled in a molding box. The sand had the following composition: Silica up to $75 \%$, Clay $12 \%$, Bentonite 3\%, Coal Dust $4 \%$ and Water $6 \%$. 
An $\mathrm{Al}$ alloy has been used for casting at different volumes (corresponding to workpieces of $\Phi 40 \mathrm{~mm}, \Phi 50 \mathrm{~mm}$ and $\Phi 60 \mathrm{~mm})$ and shell wall thicknesses $(12 \mathrm{~mm}, 11 \mathrm{~mm}, 10 \mathrm{~mm}$, $9 \mathrm{~mm}, 8 \mathrm{~mm}, 7 \mathrm{~mm}, 6 \mathrm{~mm}, 5 \mathrm{~mm}, 4 \mathrm{~mm}, 3 \mathrm{~mm}, 2 \mathrm{~mm}$ and $1 \mathrm{~mm})$. The shells were supported by green sand in the molding box, and molten metal was poured (Figure 6).
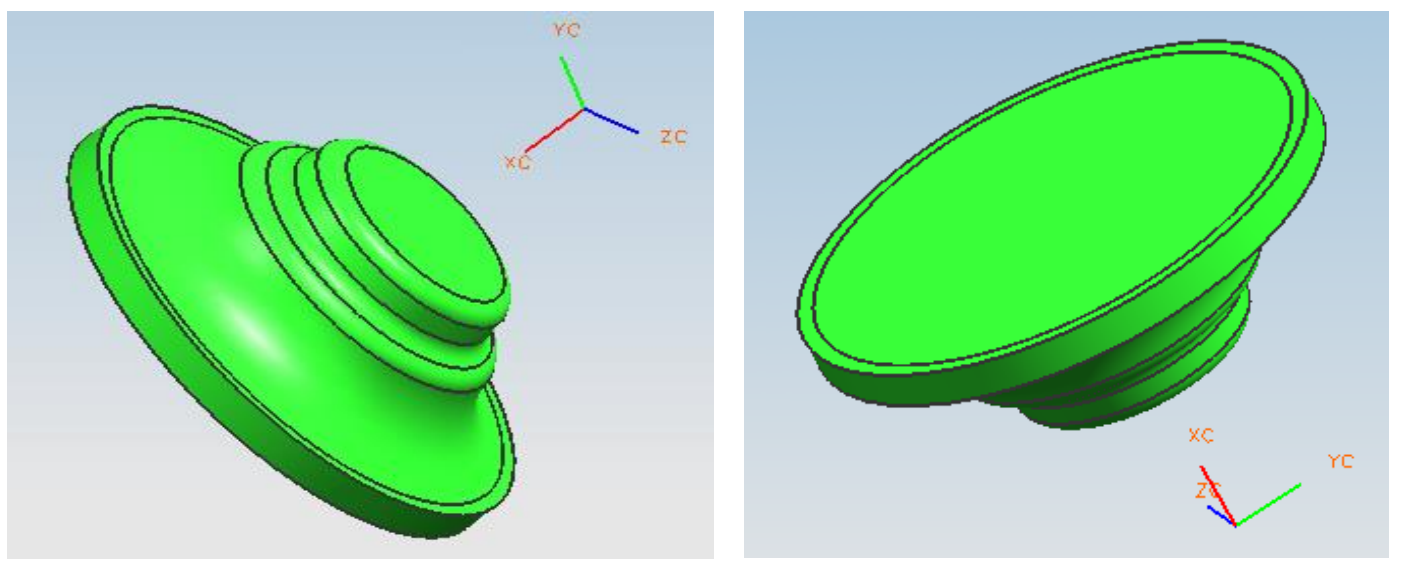

Figure 2. CAD model of the component

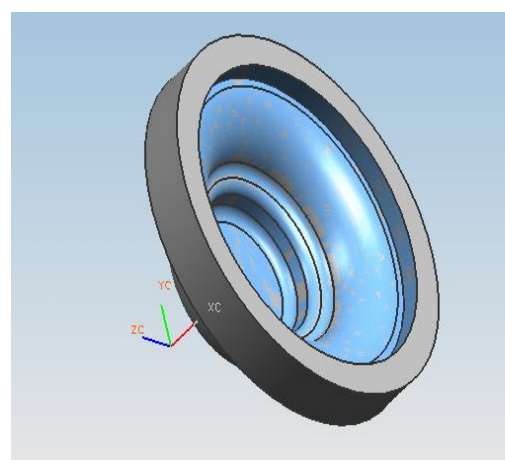

Figure 3. CAD model of shell

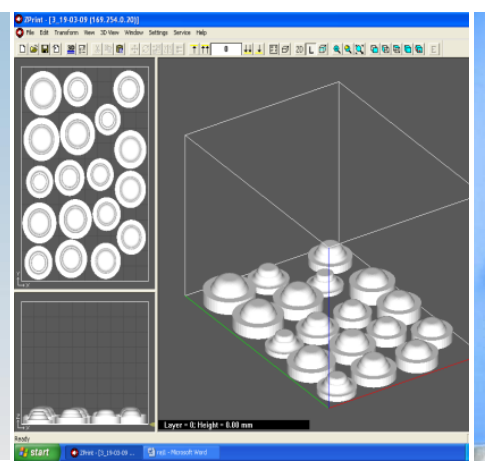

Figure 4. Triangular facets of the shells

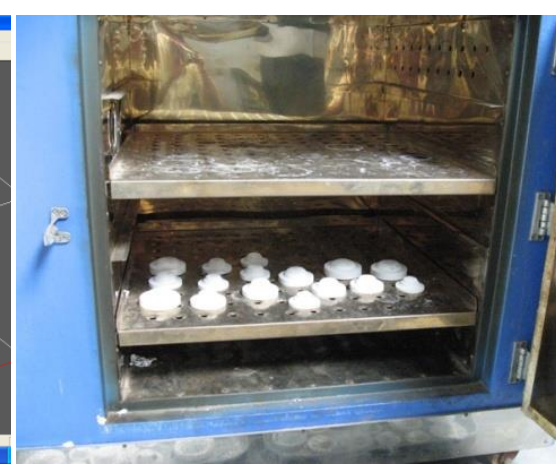

Figure 5. Post curing of shells in oven
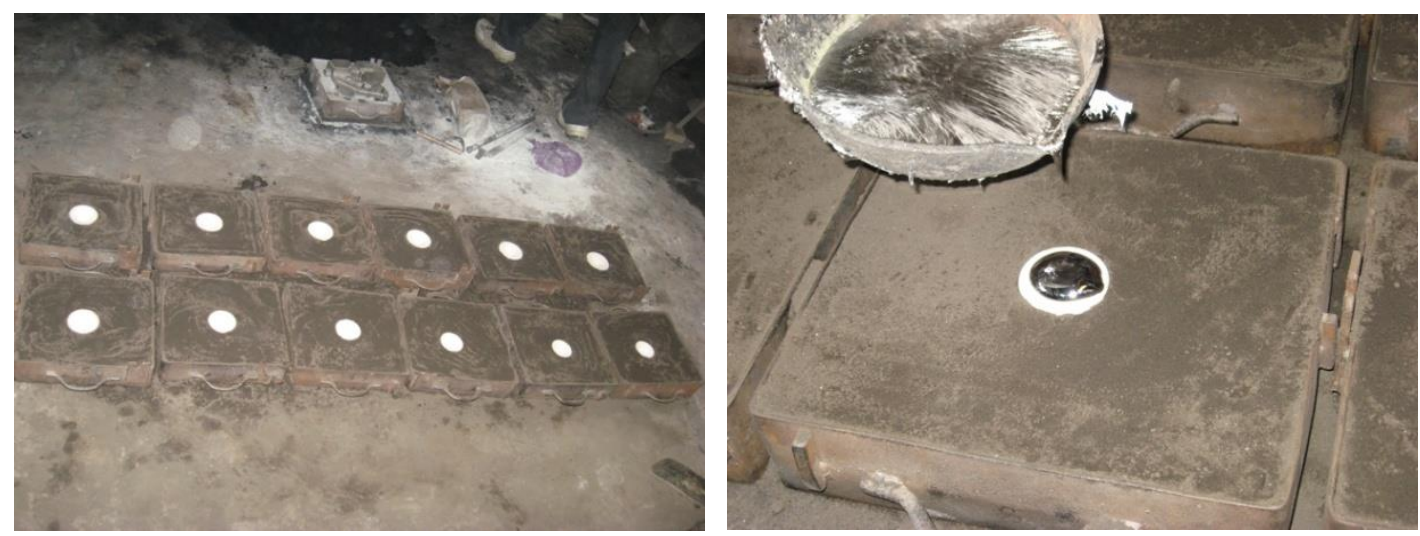

Figure 6. Pouring of molten metal in green sand supported shells 


\section{RESULTS AND DISCUSSION}

The change in temperature of the castings during the solidification process has been measured by an infrared pyrometer with respect to the time after the pouring of the molten metal into the shells. The temperature of casting has been measured by focusing the laser on the middle of the casting from the top, at regular intervals. Figures 7-9 show that for a fixed volume of the workpiece, the shell wall thicknesses (from $12 \mathrm{~mm}$ to $1 \mathrm{~mm}$ ) have an unnoticeable effect on the rate of heat transfer (for all three different volumes of workpiece).

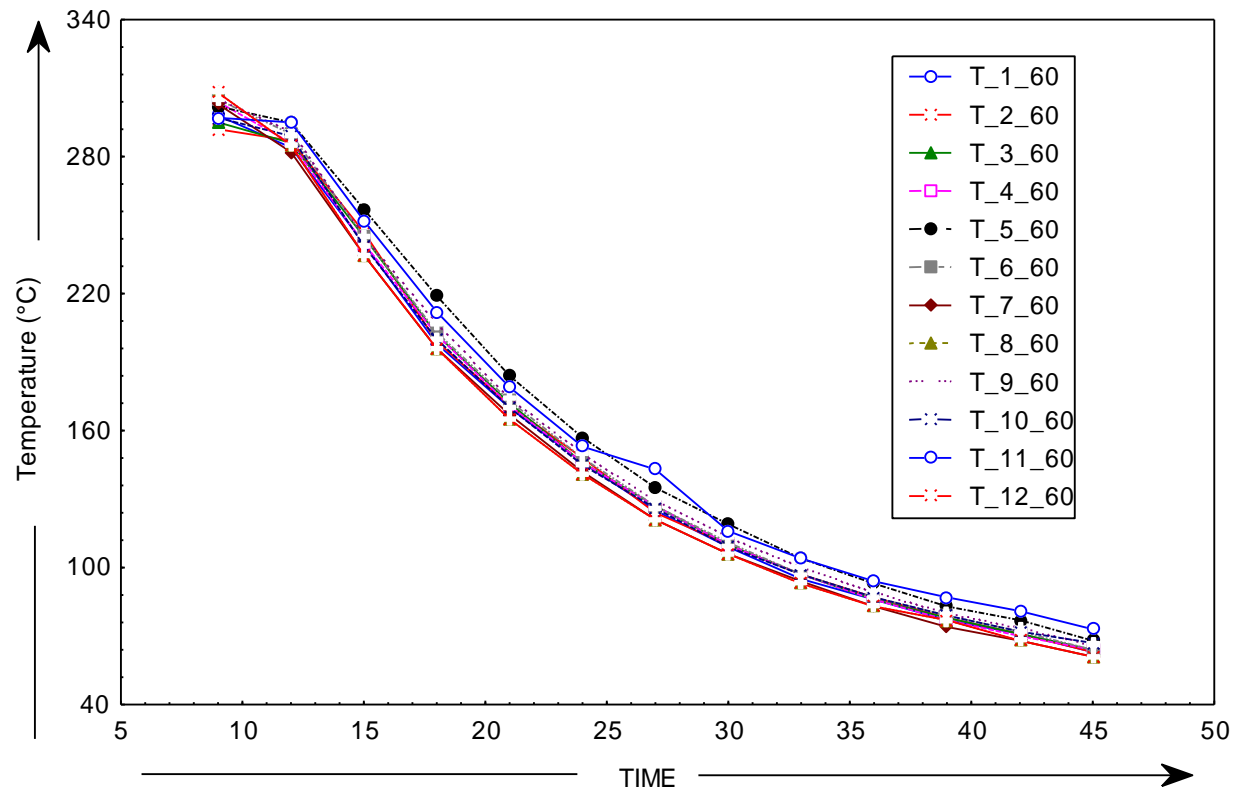

Figure 7. Combined cooling curve of $\Phi 60 \mathrm{~mm}$ workpiece

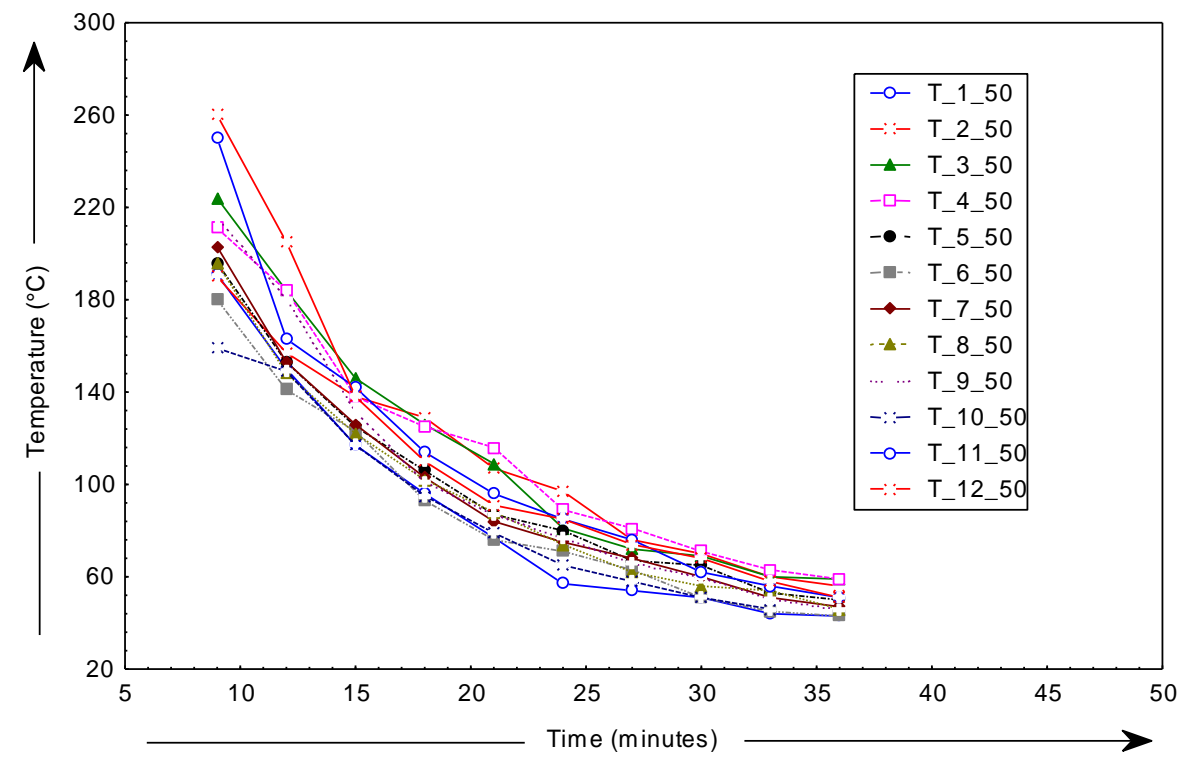

Figure 8. Combined cooling curve of $\Phi 50 \mathrm{~mm}$ workpiece 


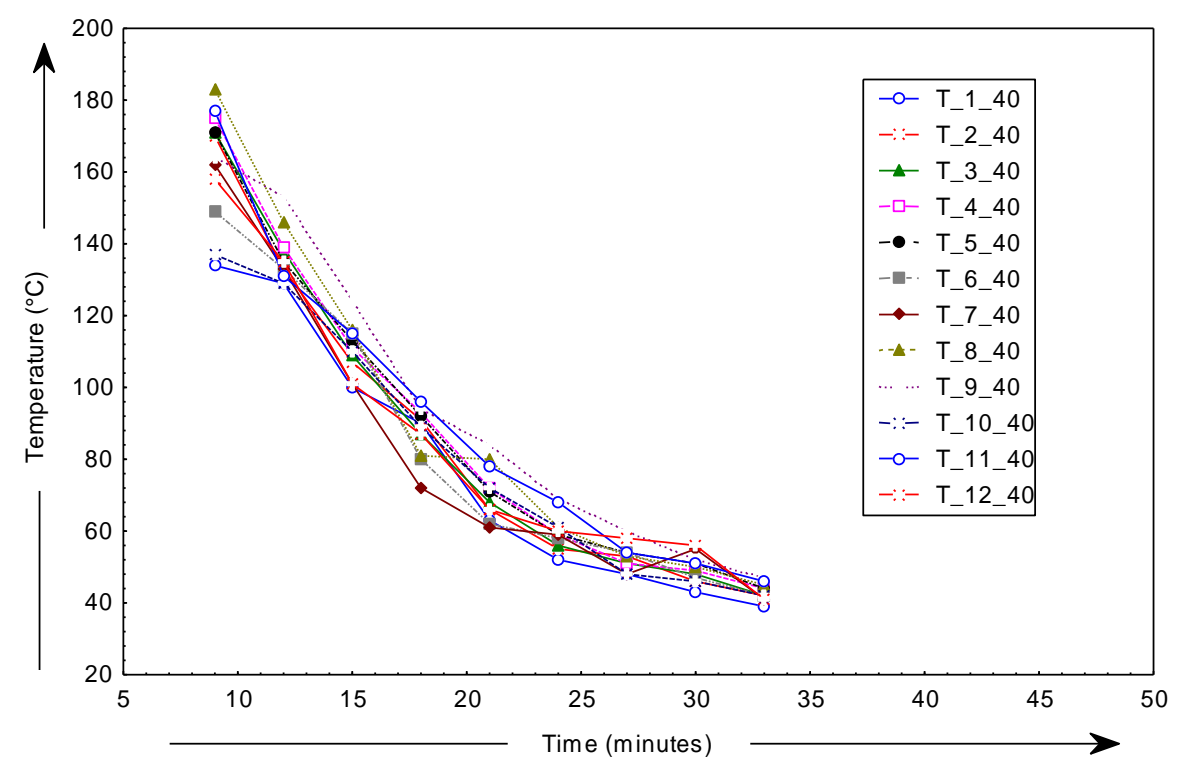

Figure 9. Combined cooling curve of $\Phi 40 \mathrm{~mm}$ workpiece

Figure 10 shows the cooling curves for a $1 \mathrm{~mm}$ shell wall thickness and three different volumes of casting, which displays a noticeable effect on the rate of heat transfer. This trend is obvious, because a higher volume will have longer solidification time, as Solidification Time $\propto\left(\frac{\text { Volume }}{\text { Surface Area }}\right)$ (Verma, 2008).

Table 1 shows the variation in the hardness of the castings prepared with respect to shell thickness $(\mathrm{mm})$. It should be noted that in casting neither a high nor low hardness is desirable. This is because if casting is of high hardness, it is usually brittle, and with a lower hardness it will be of ductile nature. In the present experimental study the variation in hardness value is not too broad. The only reason to measure and compare hardness values is to show that for an optimum sized shell thickness prepared by $3 \mathrm{DP}$, the castings produced show little variation in hardness. So there will not be any problem in its functional operations. The measurement paths for the internal and the external surfaces of the benchmark have been generated through the measurement software of GEOPAK v2.4.R10 CMM. These paths direct the movements of the CMM probe along trajectories normal to the surface of the parts. About 70 points have been measured on the external surface. For each point the machine software evaluates the deviations between the measured positions and the theoretical ones for the $\mathrm{X}, \mathrm{Y}$ and $\mathrm{Z}$ coordinates. The results of the dimensional measurements have been used to evaluate the tolerance unit (n), that is derived starting from the standard tolerance factor $\mathrm{i}$ as defined in standard UNI EN 20286-1 (1995). The values of standard tolerances corresponding to IT5-IT18 grades, for nominal sizes up to $500 \mathrm{~mm}$, were evaluated by considering the standard tolerance factor $\mathrm{i}(\mu \mathrm{m})$ indicated by the following formula, where D is the geometric mean of the range of nominal sizes in mm (Kaplas and Singh, 2008).

$$
i=0.45 D^{\frac{1}{3}}+0.001 D
$$


Table 1. Observations of hardness testing

\begin{tabular}{ccccc}
\hline \multirow{2}{*}{$\begin{array}{c}\text { Exp. } \\
\text { Serial }\end{array}$} & $\begin{array}{c}\text { Shell Thickness } \\
(\mathrm{mm})\end{array}$ & \multicolumn{3}{c}{ Rockwell Hardness No.(HRB) } \\
\cline { 3 - 5 } No. & & \multicolumn{3}{c}{ Workpiece Diameter } \\
\cline { 3 - 5 } & 12 & 57 & 54 & 51 \\
1 & 11 & 56 & 57 & 53 \\
2 & 10 & 55 & 59 & 58 \\
3 & 9 & 56 & 52 & 52 \\
4 & 8 & 52 & 57 & 54 \\
5 & 7 & 54 & 58 & 58 \\
6 & 6 & 56 & 58 & 56 \\
7 & 5 & 55 & 59 & 53 \\
8 & 4 & 54 & 59 & 54 \\
9 & 3 & 56 & 55 & 56 \\
10 & 2 & 57 & 58 & 52 \\
11 & 1 & 52 & 51 & 57 \\
12 & & &
\end{tabular}

Table 2. IT grades for outer diameters of $\Phi 60 \mathrm{~mm}, \Phi 50 \mathrm{~mm}$ and $\Phi 40 \mathrm{~mm}$

\begin{tabular}{|c|c|c|c|c|c|c|}
\hline $\begin{array}{c}\text { Shell } \\
\text { Thickness } \\
\text { mm) }\end{array}$ & $\begin{array}{c}\mathrm{D}_{\mathrm{JM}} \\
\text { for } \boldsymbol{\Phi} 60 \\
\mathrm{~mm}\end{array}$ & $\begin{array}{c}\text { IT Grade } \\
\text { for } \\
\mathrm{D}_{\mathrm{JN}}= \\
\text { Ф60 mm }\end{array}$ & $\begin{array}{l}\mathrm{D}_{\mathrm{JM}} \\
\text { for } \boldsymbol{\Phi 5 0} \\
\mathrm{mm}\end{array}$ & $\begin{array}{c}\text { IT } \\
\text { Grade } \\
\text { for } \\
\mathrm{D}_{\text {JN }}= \\
\mathbf{\Phi 5 0} \\
\mathrm{mm}\end{array}$ & $\begin{array}{c}\mathrm{D}_{\mathrm{JM}} \\
\text { for } \boldsymbol{\Phi} 40 \\
\mathrm{~mm}\end{array}$ & $\begin{array}{c}\text { IT Grade } \\
\text { for } \\
\text { D }_{\mathrm{JN}}= \\
\mathbf{\Phi} 40 \mathrm{~mm}\end{array}$ \\
\hline 12 & 59.855 & IT10 & 49.815 & IT11 & 39.900 & IT10 \\
\hline 11 & 59.605 & IT12 & 49.825 & IT11 & 39.940 & IT8 \\
\hline 10 & 59.820 & IT10 & 49.875 & IT10 & 39.905 & IT9 \\
\hline 9 & 59.810 & IT11 & 49.780 & IT11 & 39.790 & IT11 \\
\hline 8 & 59.585 & IT12 & 49.825 & IT11 & 39.815 & IT11 \\
\hline 7 & 59.865 & IT10 & 49.715 & IT12 & 39.890 & IT10 \\
\hline 6 & 59.810 & IT10 & 49.375 & IT14 & 39.720 & IT12 \\
\hline 5 & 59.555 & IT12 & 49.700 & IT12 & 39.740 & IT12 \\
\hline 4 & 59.445 & IT12 & 49.845 & IT10 & 39.695 & IT12 \\
\hline 3 & 59.455 & IT12 & 49.760 & IT11 & 39.445 & IT13 \\
\hline 2 & 59.890 & IT9 & 49.415 & IT13 & 39.510 & IT13 \\
\hline 1 & 59.540 & IT12 & 49.590 & IT13 & 39.705 & IT12 \\
\hline
\end{tabular}

In fact, the standard tolerances are not evaluated separately for each nominal size, but for a range of nominal sizes. For a generic nominal dimension $D_{J N}$, the number of tolerance units $n$ is evaluated as follows:

$$
n=1000\left(D_{J N}-D_{J M}\right) / i
$$


where $D_{J M}$ is the measured dimension. The tolerance is expressed as a multiple of $i$ : for example, IT14 corresponds to $400 i$ with $n=400$. Table 2 shows a classification of different IT grades according to UNI EN 20286-1 (Singh and Singh, 2009c). As observed from Table 2, all shell wall thicknesses are acceptable as per the ISO standard UNIEN 20286-I (1995). Furthermore, it is observed that the shell production cost and time is decreased, as the shell wall thickness decreases from $12 \mathrm{~mm}$ to $1 \mathrm{~mm}$ (Figures 11-12). This is due to the fact that the material used to produce the shell decreases as the shell thickness decreases. These are in line with the observations made by other investigators (Kaplas and Singh, 2008). So, keeping in mind the cost effectiveness of the process, a $1 \mathrm{~mm}$ shell wall thickness is recommended.

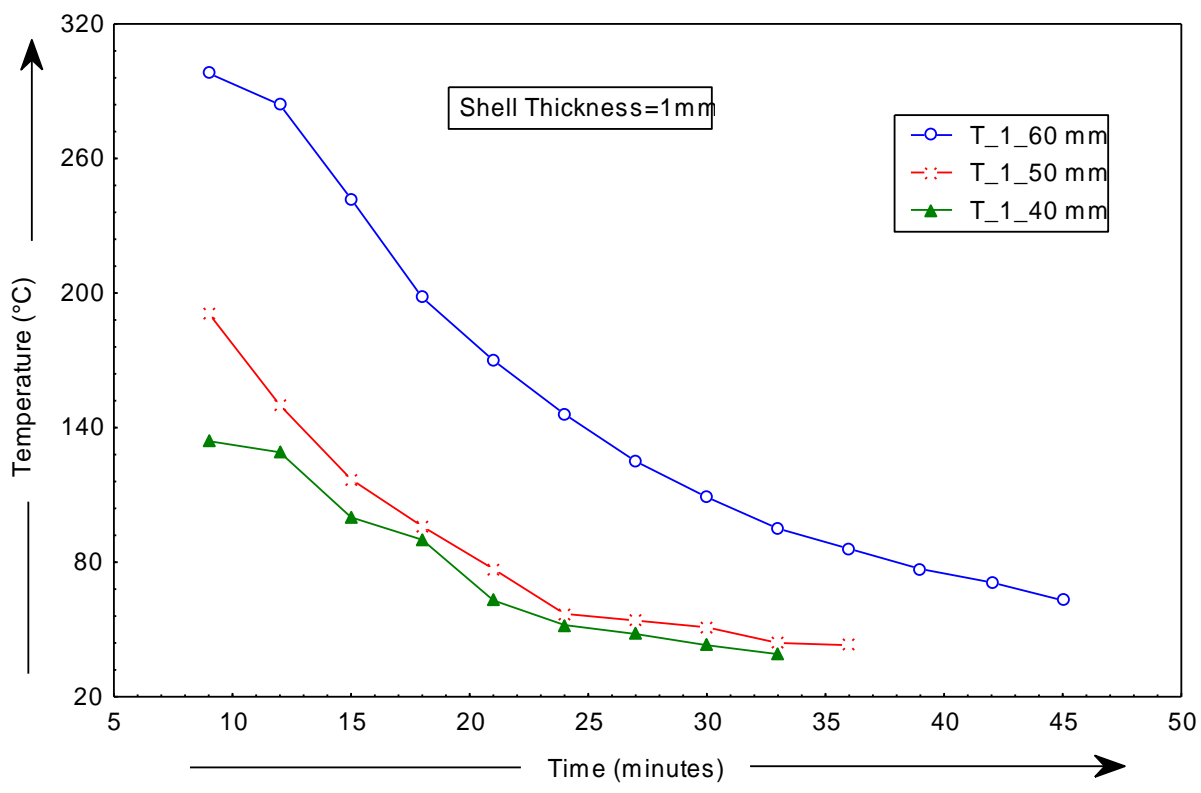

Figure 10. Cooling curve at $1 \mathrm{~mm}$ shell thickness

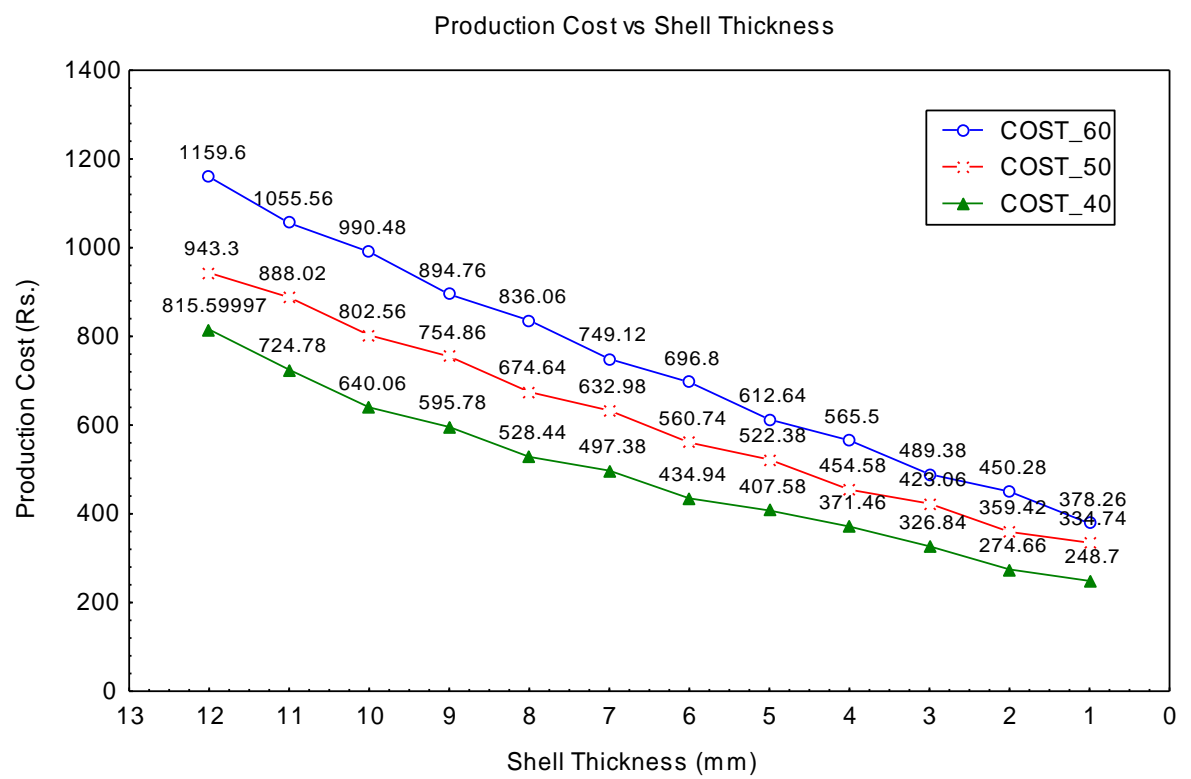

Figure 11. Shell wall thickness vs. shell production cost 


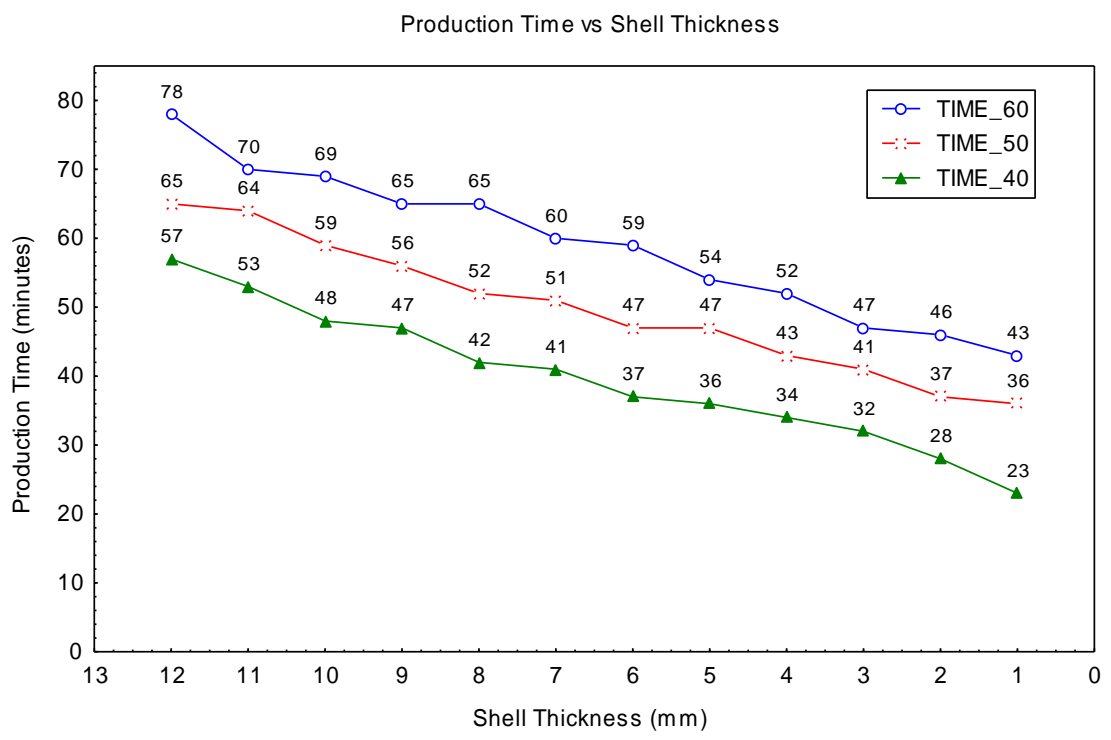

Figure 12. Shell wall thickness vs. shell production time

\section{CONCLUSIONS}

On the basis of the experimental observations made on Al alloy castings, obtained from different shell wall thicknesses, the following conclusions can be drawn:

i) It is feasible to reduce the shell thickness from the recommended value of 12 $\mathrm{mm}$ to $1 \mathrm{~mm}$ for $\mathrm{Al}$ castings. The tolerance grades of the castings produced from different thicknesses are consistent with the permissible range of tolerance grades (IT grades) as per UNI EN 20286-I (1995).

ii) The results indicate that the hardness is almost the same for all thicknesses from $12 \mathrm{~mm}$ to $1 \mathrm{~mm}$. This is supported by the cooling curves, as there are negligible changes in the heat transfer.

iii) The shell production cost and time is reduced by $67.38 \%$ and $44.87 \%$ (for a workpiece diameter of $60 \mathrm{~mm}$ ), $64.51 \%$ and $44.62 \%$ (for a workpiece diameter of $50 \mathrm{~mm}$ ), and $69.50 \%$ and $59.64 \%$ (for a workpiece diameter of $40 \mathrm{~mm}$ ), respectively when a $1 \mathrm{~mm}$ shell thickness is used for the production of Aluminum castings.

iv) There is an unnoticeable effect on the volume of the workpiece from the reduction in shell wall thickness.

\section{Scope of Future Work}

i) The experimental investigations may be extended to other geometries and volume ranges of workpieces.

ii) Furthermore, different workpiece volume ranges may be optimized at $1 \mathrm{~mm}$ shell wall thickness with regard to their mechanical properties and tolerance grades (as in the present study), using the design of experiments technique (like Taguchi Analysis) with a greater number of input parameters, such as weight density, metal/alloy type, etc. 


\section{ACKNOWLEDGEMENT}

The author is thankful to DST, New Delhi for financial support, Grant No. SR/FTP/ETA-81/2010.

\section{REFERENCES}

Bassoli E., Gatto A., Luliano, L. and Violentte, M.G. 2007. 3D printing technique applied to rapid casting. Rapid Prototyping Journal, 13: 148-155.

Bernard, A., Delplace, Charles, J., Perry, N. and Gabriel, S. 2003. Integration of CAD and rapid manufacturing for sand casting optimization. Rapid Prototyping Journal, 5: 327-333.

Chan, W.K., Wong, Y.W., Chua, C.K., Lee, C.W. and Feng, C. 2003. Rapid manufacturing techniques in the development of an axial blood pump impeller. Proceedings of IMechE Part H: Journal of Engineering in Medicine, 217(H6): 469-475.

Cheah, C.M., Chua, C.K., Lee, C.W., Feng, C. and Totong, K. 2005. Rapid prototyping and tooling techniques: a review of applications for rapid investment casting. International Journal of Advanced Manufacturing Technology, 25(3-4): 308320.

Chhabra, M. and Singh, R. 2011. Rapid casting solutions: a review. Rapid Prototyping Journal, 17(5): 328-350.

Chua, C.K. and Ho, S.L. 1999a. Rapid tooling technology - Part 1: A comparative study. International Journal of Advanced Manufacturing Technology, 15(8): 604-608.

Chua, C.K. and Ho, S.L. 1999b. Rapid tooling technology - Part 2: Case study using arc spray metal tooling. International Journal of Advanced Manufacturing Technology, 15(8): 609-614.

Chua, C.K., Feng, C., Lee, C.W. and Ang, G.C. 2005. Rapid investment casting: direct $\&$ indirect approaches via model maker II. International Journal of Advanced Manufacturing Technology, 25: 26-32.

Dimitrov, D., Schreve, K. and de Beer, N. 2006. Advances in three dimensional printing - state of the art and future perspectives. Rapid Prototyping Journal, 12(3): 136147.

Dimitrov, D., van Wijck, W, de Beer, N. and Dietrich, J. 2007. Development, evaluation and selection of rapid tooling process chains for sand casting of functional prototypes. Journal of Engineering Manufacture, 221(B9): 1441-1450.

Kaplas, M. and Singh, R. 2008. Experimental investigations for reducing wall thickness in zinc shell casting using three dimensional printing. Proceedings of IMechE Part C: Journal of Mechanical Engineering Sciences, 222(C12): 2427-2431.

Karapatis, N.P., van Griethuysen, J.P.S. and Glardon, R. 1998. Direct rapid tooling: a review of current research. Rapid Prototyping Journal, 4(2): 77-89.

Lee, C.W., Chua, C.K., Cheah, C.M., Tan, L.H. and Feng, C. 2004. Rapid investment casting: direct and indirect approaches via fused deposition modelling. International Journal of Advanced Manufacturing Technology, 23(1-2): 93-101.

Radstok, E. 1999. Rapid tooling. Rapid Prototyping Journal, 5(4): 164-168.

Sachs, E.M., Haggerty, J.S., Cima, M.J. and Wiliams, A.P. 1994. Three dimensional printing techniques. US Patent No. US 005340656. 
Singh, J.P. 2008b. Experimental investigations for generating cost effective rapid castings of different alloys using three dimensional printing. Master Thesis, P.T.U. Jalandhar, India.

Singh, J.P. and Singh, R. 2009a. Investigations for statistically controlled rapid casting solution of low brass alloys using three dimensional printing. International Journal of Rapid Manufacturing, 1(2): 208-221.

Singh, J.P. and Singh, R. 2009b. Investigations for statistically controlled rapid casting solution of lead alloys using three dimensional printing. Proceedings of IMechE Part C: Journal of Mechanical Engineering Sciences, 223(C9): 2125-2134.

Singh, R. 2008a. Application of three dimensional printing (3DP) in generating costeffective rapid prototype for casting industry. Souvenir of $11^{\text {th }}$ Punjab Science Congress, Patiala, India.

Singh, R. 2008c. Three dimensional printing for casting applications: a state of the art review and future perspectives. Souvenir of International Conference on Advances in Materials and Processing Technologies, Manama, Kingdom of Bahrain, pp. 311.

Singh, R. 2011a. Comparison of statistically controlled rapid casting solutions of zinc alloys using three dimensional printing. International Journal of Automotive and Mechanical Engineering, 3: 293-305.

Singh, R. 2011b. Process capability study of rapid casting solution for aluminium alloys using three dimensional printing. International Journal of Automotive and Mechanical Engineering, 4: 397-404.

Singh, R. and Singh, J.P. 2009c. Comparison of rapid casting solutions for lead and brass alloys using three dimensional printing. Proceedings of IMechE Part C: Journal of Mechanical Engineering Sciences, 223(C9): 2117-2123.

Singh, R. and Verma, M. 2008. Investigations for reducing wall thickness of aluminium shell casting using three dimensional printing. Journal of Achievements in Materials and Manufacturing Engineering, 31(2): 565-569.

Stampfl, J. and Liska, R. 2005. New materials for rapid prototyping applications. Macromolecular Chemistry and Physics, 206: 1253-1256.

IOS (Italian Organization for Standardization). 1995. UNI EN 20286-1. ISO system of limits and fits. Bases of tolerances, deviations and fits. Italy, UNI.

Verma, M. 2008. Investigations for reducing wall thickness in aluminium shell casting using 3DP. Master Thesis, P.T.U. Jalandhar, India.

Wang, W., Conley, J.G. and Stoll, H.W. 1999. Rapid tooling for sand casting using laminated object manufacturing process. Rapid Prototyping Journal, 5(3): 134140. 